\title{
A Study on the Elasticity of Labor Supply of Chinese Taxi Drivers
}

\author{
Yunqiu Tu \\ School of Economics \& Management, Shanghai Maritime University, Shanghai, China \\ Email: tuyunqiu@126.com
}

How to cite this paper: Tu, Y. Q. (2021). A Study on the Elasticity of Labor Supply of Chinese Taxi Drivers. Open Journal of Business and Management, 9, 2101-2118. https://doi.org/10.4236/ojbm.2021.95111

Received: June 23, 2021

Accepted: August 7, 2021

Published: August 10, 2021

Copyright (c) 2021 by author(s) and Scientific Research Publishing Inc. This work is licensed under the Creative Commons Attribution International License (CC BY 4.0).

http://creativecommons.org/licenses/by/4.0/

\begin{abstract}
The theory of labor supply consists of two major theories: neoclassical theory and reference dependence theory. However, the theories are both interoperable and contradictory. Through the literature review of the development of labor supply theories and combined with the study on current development status of China's taxi industry, this paper made a study on the elasticity of labor supply of Chinese taxi drivers. The theories and models of labor supply are sorted out and analyzed by taking the Chinese taxi industry as an example to be the basis for a further empirical research.
\end{abstract}

\section{Keywords}

Labor Supply, Wage Elasticity, Neoclassical Economics

\section{Introduction}

Generally speaking, according to the neoclassical labor supply model, we predict that working hours should respond positively to temporary positive wage changes, that is, workers should work more when wages are higher, and consume more when wages are lower. Although this prediction is in line with our daily thinking, it is difficult to find empirical support.

On the other side, with the increase in people's income, taxis have become an alternative means of transportation for people to travel. As an important part of urban passenger transportation and an important supplement to conventional public transportation (Doran, 2014), it directly reflects the level of urban passenger transportation and the diversity of residents' travel options. It is an important tool that can meet the daily travel needs of groups with a certain ability to pay and the special travel needs of the general public, and provide transportation services for major state and foreign affairs activities (Farber, 2005). Over the past two decades, as people's living standards have gradually improved, people's 
requirements for transportation have also increased significantly. As a means of transportation, taxis are favored by a large number of short-distance travelers due to their speed and convenience. As the number of taxis continues to grow, taxi traffic has become an important part of the total urban road traffic. Taxis account for an increasing proportion of the city's conventional public transportation. Taxi traffic has become an important part of the total urban road traffic. The increase and development of taxis is an important sign of rapid economic development. So what is truth about the wage elasticity of the taxi driver's labor supply? Different from general workers, taxi drivers face wages that fluctuate within a short period due to demand shocks caused by many factors, such as weather, traffic, day-of-the-week effects, holidays, and conventions. Although rates per hour/mile/job are set, during busy periods, drivers spend less time searching for customers and jobs and thus earn a higher hourly/daily wage. The wages tend to be correlated within the short periods and uncorrelated across periods.

There are mainly two competing theories driving these empirical findings: 1) the neoclassical model of labor supply; 2) reference-dependent model. In the neoclassical theory of labor supply, an agent needs to decide how many hours to work facing the hourly rate of earning. Due to the diminishing marginal utility of income, the marginal utility of leisure relative to the marginal utility of additional income from extra working time becomes larger as the total working time increases.

In a reference-dependent model, a driver's preferences reflect both the standard consumption utility of income and leisure and reference dependent "gain-loss" utility, with their relative importance tuned by a parameter. A driver is loss-averse; but he has a daily target for hours as well as income and working longer than the hours target is a loss, just as earning less than the income target is. Finally, this model endogenizes the targets by setting a driver's targets equal to his theoretical rational expectations of hours and income, reflecting the belief that drivers in steady state have learned to predict their distributions.

If the weight of gain-loss utility is small, this model mimics a neoclassical labor supply model, so that the elasticity of hours with respect to earnings per hour is normally positive. If the weight of gain-loss utility is large, perfectly anticipated changes in earnings per hour still have this neoclassical implication because gain-loss utility then drops out of a driver's preferences. However, unanticipated changes may then have non-neoclassical implications. In particular, when the income target has an important influence on a driver's stopping decision, a driver who values income but is "rational" in the reference-dependent sense of prospect theory will tend to have a negative elasticity of hours with respect to earnings per hour.

Due to the different political, economic and social backgrounds between China and the West, the western labor supply theory is not entirely suitable for China's national conditions. Therefore, this article will study the labor supply 
and wage elasticity of taxi drivers on the basis of the current status of the Chinese taxi industry.

\section{Literature Review on Labor Supply and Wages}

The literature of neoclassical labor supply, which was introduced by Lucas and Rapping (1969) predicts a positive response to positive shock in wages. It predicts that a driver would work longer if hourly earnings increases in a short horizon. The simple correlation between changes over time in the hours worked of individuals and corresponding changes in their wage rates has been shown to be negative at least in the U.S. data. [See, for example, Abowd and Card (1984)].

In order to provide an accurate estimation, it would be ideal to have wages that are relatively constant within a day but uncorrelated across days. There is an emerging literature on labor supply in settings where workers are free to set their labor supply. Oettinger (1999) investigates the days of work of stadium vendors at baseball games. The stadium vendors are approved to sell at games and are free to work or not work at any particular game without notice to their employer. They receive a fixed commission rate on sales. Their hours are fixed for any game for which they show up to work to the extent that they are not supposed to leave early. The interesting labor supply margin in this case is the number of days particular vendors choose to work. Oettinger concludes that there is a substantial positive intertemporal labor supply elasticity implicit in the daily participation decisions of the vendors he studies.

Camerer, Babcock, Loewenstein, and Thaler (1997) propose to use labor supply data of NYC taxi drivers. These drivers lease their taxis for a prespecified period (day, week, or month) for a fixed fee, are responsible for fuel and some maintenance, and keep 100 percent of their fare income after paying fixed costs. They are free to drive as much or as little as they want during the lease period. This leasing arrangement is close to the incentive theorist's first-best solution to the firm-worker principal-agent problem of selling the firm to the workers. They show that the earnings per hour are uncorrelated across days but positively correlated within a day. The core of their analysis consists of computing a daily wage rate as the ratio of daily income to daily hours. They then regress the logarithm of daily hours on the logarithm of this wage rate and find a significant and substantial negative elasticity of labor supply. Contradicting to the prediction of neoclassic models, they find the estimated wage elasticities are substantially negative. They interpret the findings as drivers make the labor supply decision at a one-day horizon, instead of intertemporal substituting labor and leisure across multiple days. Furthermore, they propose that drivers' preferences are reference dependent, particularly income dependent, meaning that drivers set a loose daily income target and quit working once they reach that target. They conclude that their result is consistent with a target earnings model, in which drivers stop working after reaching their target daily income. They argue further that this is inconsistent with a standard neoclassical model of labor supply. 
Doran (2014) investigated the wage elasticities for different length periods of time periods. Using a new NYC taxi driver data, three models were considered, -i.e. neoclassical model, daily income target as in Fehr and Goette (2007) and expectation based on income targeting as introduced in Köszegi and Rabin (2006). Larger negative wage elasticity in short term wage changes were found, compared to long term wage changes. The results confirmed that neoclassical model's inability to explain negative wage elasticities in short-term wage increase. Camerer et al. (9)'s approach adequately addressed the short-term effect and more advanced expectation-based income targeting approach as proposed by Köszegi and Rabin (2006) outperformed the other two models by accounting for the differences in both short-term and long-term wage changes.

Farber (2015) obtains all records of all trips taken in NYC taxis from 2009 to 2013. The new dataset shows that drivers tend to respond positively to unanticipated as well as anticipated increases in earning opportunities. Additionally, using a discrete choice stopping model, the probability of a shift ending is strongly positively related to hours worked but at best weakly related to income earned. The new findings from this dataset reject the previous reference-dependent models.

Regarding the relationship between wages and labor productivity, Luo and Zhao (2013) analyzed the coexistence of high investment and low income in China and found that the large gap between labor productivity and wage growth is an important factor affecting labor income reduction. Guo (2000) took Chinese manufacturing industry as an example, and compared the two indicators of labor productivity growth rate and the proportion of wages in the added value of manufacturing output. He found that the gap in labor productivity has led to Chinese low labor cost advantage not being brought into play. It can be seen that most domestic scholars believe that there is a mutually reinforcing relationship between wages and labor productivity.

Regarding the synchronization of wages and labor productivity, some scholars believe that wage growth cannot be synchronized with labor productivity. Lu (2007) took Chinese manufacturing industry as an example and used data from 1991 to 2005 to conduct research and found that the average annual growth rate of wages was higher than the average annual growth rate of per capita wages in the same period. Du and Qu (2009) conducted a study based on the data of Chinese manufacturing enterprises above designated size from 2000 to 2007, and found that the growth rate of wages is much lower than the growth rate of labor productivity. Zhang and Liu (2012) selected Chinese non-state-owned large-scale manufacturing enterprises as the research object, and selected the data interval from 1998 to 2007. They combed and compared the historical trends of wages and labor productivity in Chinese manufacturing enterprises and made a correlative analysis. The results show that regardless of the original value or the growth rate data, the labor productivity index of Chinese non-state-owned large-scale manufacturing industry is significantly higher than its wage index, 
and there was a trend that the gap between the two indicators would getting bigger over time.

There are also some scholars believe that it is possible and necessary for wage growth and labor productivity to synchronize. Zheng (2012) studied the relationship between wages and production efficiency in Guangdong Province in stages. The research shows that the influence of wages in Guangdong Province on production efficiency has a tendency to increase over time. Xu (2016) sorts out the relationship between wages and labor productivity in different periods. The results show that the two have different proportional relationships in different historical periods. However, the overall trend shows that there is a simultaneous growth trend, indicating that the two have increased possibility of synchronization. Cai (2001) believes that China has entered the Lewis turning point, that is, labor resources have turned from surplus to shortage, and thus wages have risen. Only by achieving the synchronization of wage growth and labor productivity can the stable operation of the macro economy be ensured. Lin et al. (2013) used impulse response and variance decomposition to analyze the relationship and degree of the interaction between wages and labor productivity, and found that there is a continuous interaction between wage increases and labor productivity growth. Li (2005) elaborated on the imbalance of income distribution in China, and suggested paying attention to the income gaps in different industries, groups of people and different regions, actively mediating the gaps, ensuring that wage growth and labor productivity growth are synchronized, and gradually narrowing the unbalanced development gap.

\section{An Analysis of the Historical Evolution and Current Situation of Labor Supply Behavior in China's Taxi Industry}

\subsection{The Development Background and History of China's Taxi Industry}

The taxi system is an important part of the urban transportation system. It is a transportation operation mode derived from meeting the individual travel needs of groups with the corresponding ability to pay. It improves the convenience, flexibility and comfort of residents' travel it played an important role. At the same time, as an important supplement to the general urban transportation system, the taxi system is also of great significance in establishing a good city image and meeting higher-level transportation needs.

Taxi was first introduced into China in 1903 in Harbin, however, the taxi industry declined due to the political and economic turmoil caused by the Second World War. Since the reform and opening up in China, the taxi industry has achieved rapid development in China.

In the context of increasing demand for diversified travel, the number of taxis and the number of employees in the taxi industry have increased significantly, 
which has also made a certain contribution to the development of Chinese transportation industry.

\subsection{The Development Status of China's Taxi Industry}

\subsubsection{Existing Problem}

At present, the comprehensive passenger transportation system of various cities in our country is facing a variety of different problems and challenges, as is the same for the taxi industry, which is an important part of the urban public transportation system.

It can be seen from Figure 1 that the number of taxis in China experienced a rapid growth from 2011 to 2016. However, with the impact of online car-hailing service, it has entered a relatively stable plateau after 2017. Compared with the past three decades, the impact of private cars and online ride-hailing service on taxis has continued to increase, taxis no longer face the problem of empty load rate, but quite a lot of taxis are stuck in warehouses. Take Shanghai as an example, there are about 51,000 parade taxis in the city, and only about half of them are actually operated daily.

In response to the imbalance between supply and demand in the taxi industry, local governments have mainly made adjustments to the taxi industry from the following aspects. The first is to increase the total number of taxi vehicles to increase the scale of supply, and increase year by year with the continuous expansion of demand; second, the government focuses on how to expand the actual supply of taxis and how to maximize the average in the taxi industry. The daily mileage is used to maximize the potential of vehicles and passengers; finally, taxi prices are used as an important tool to regulate supply and demand. The growth of cities due to factors such as economy and population is certainly related to the expansion of demand for taxis, but the actual price in the industry is lower than

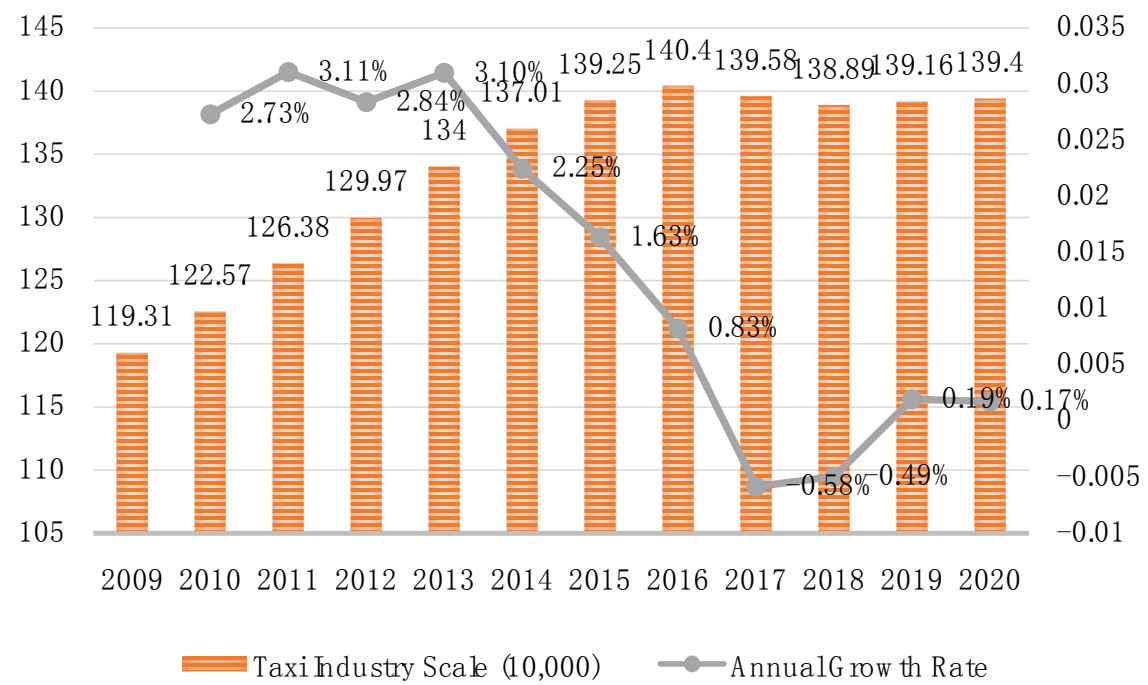

Figure 1. Chinese taxi industry scale $\left({ }^{\star}\right.$ Source: 2020 Statistical Communiqué on the Development of the Transportation Industry by MOT). 
the equilibrium point of market supply and demand is also a key factor leading to short supply. Therefore, price should be used as an important tool to regulate supply and demand.

At the same time, with the advent of the "Internett" era, the number of taxi-hailing software in the market continues to increase, and the taxi industry is also undergoing unprecedented changes. The emergence of "special vehicles" broke the monopoly of the original taxi market. In many cities, taxi drivers went on strike and smashed and squeezed taxis. Taxi drivers had difficulty competing with taxi drivers due to a relatively high share of management fees. Sharing economy models such as online car-hailing platforms have emerged. Traditional taxis are still subject to government price control and license control. Online car-hailing has the characteristics of high flexibility in terms of working hours and wages. Certainly shock. The online car-hailing platform plays an important role in the sharing economy model. The online car-hailing relies on the network platform to release information, effectively solving the problem of information asymmetry in the taxi market, and improving production efficiency to a certain extent. Therefore, in terms of policy and technology, the large number of "special vehicles", that is, online car-hailing, will lead to excessive competition between traditional taxi drivers and online car-hailing drivers, and the market cannot be well developed.

In order to maintain the stability and fairness of the market, local governments have introduced a series of measures to regulate the private car market, and introduced relevant policies to maintain and maintain the normal operation and development of the taxi industry.

\subsubsection{The Development Trend of China's Taxi Industry}

From the perspective of competition trends in the industry, the emergence of online car-hailing and private cars under the sharing economy model has had a certain impact on the traditional taxi industry. Although it did not pose a fatal threat to the original taxi industry, the rental the car market is a monopoly market, and the development of the online car-hailing model will reduce industry profits in the long run, affecting taxi companies and taxi drivers. Within the taxi industry, due to the increase in the total number of taxis in various cities, to a certain extent, the competition within the industry has intensified. The uninterrupted increase in competition both inside and outside the industry will lead to changes in the taxi industry to a certain extent.

From the perspective of service trends, under the background of the increasing number of private cars and online car-hailing, industry competition has intensified. In terms of objective demand, traditional taxis are required to improve service quality and increase their own competitiveness. Since the traditional taxi industry is a monopolistic market, there is no large external competition in the consumer market. Therefore, in the traditional sense, taxi drivers only have competitive pressure from operating license plates and vehicle management 
rights at the beginning of their entry into the industry, but not from services. Competitive pressures of suppliers. As the sharing economy model continues to spread, the personalized and diversified needs of passengers in the market will continue to increase. Therefore, future rental services will continue to improve service quality and meet the personalized needs of passengers.

In general, the development trend of China's taxi industry is the increasing competition inside and outside the industry, the efficient transformation of management models, and the transformation of services to personalized and diversified services. At the same time, some cities in China have already started the large-scale reconstruction of taxi companies led by the government in the taxi industry. The introduction of the reconstruction policy not only facilitates the branding effect of the traditional taxi industry, but objectively promotes the promotion of taxi drivers. The quality of service, and from the perspective of a large-scale company established by the government, can provide drivers with better protection, more services, and a better working environment for drivers.

\subsection{The Development Status of China's Taxi Driver Labor Supply}

\subsubsection{Neoclassical Economics Labor Supply Theory}

In neoclassical economics, labor supply decision-making is regarded as an individual's balance between consumption and leisure. Through the optimal choice of leisure, individual laborers can provide the optimal labor supply accordingly. The formation of this labor supply depends not only on the wages and income levels that individual laborers can obtain in the labor process, but also on a series of exogenous variables such as expected wage levels, tax policies, and labor systems.

In the labor theory of neoclassical economics, when the market price of labor, that is, wages, rises, individual workers will reduce their demand for leisure while increasing their demand for labor. Conversely, when the market price of labor, that is wages, decreases, Self-employed workers will increase the demand for leisure and reduce the demand for labor. This is a substitution effect. When wages increase, self-employed workers will replace leisure with more work. If leisure is assumed as a commodity in the market, when the income of laborers increases, people will increase their demand for leisure goods and reduce the supply of labor at the same time (Figure 2).

This is the income effect. The degree of individual labor's response to changes in wage levels depends on the magnitude of the two effects reflected in the labor market. If the income effect is smaller than the substitution effect, when the price of labor in the market, that is, wages, increases, people's Supply will rise accordingly, and when the income effect is greater than the substitution effect, when the price of labor in the labor market, that is, wages, increases, people's labor supply will fall instead, that is, the demand for leisure goods is greater. This is the so-called "backward-curved labor supply curve" in neoclassical labor economics. It more intuitively expresses the individual laborer's trade-off between 


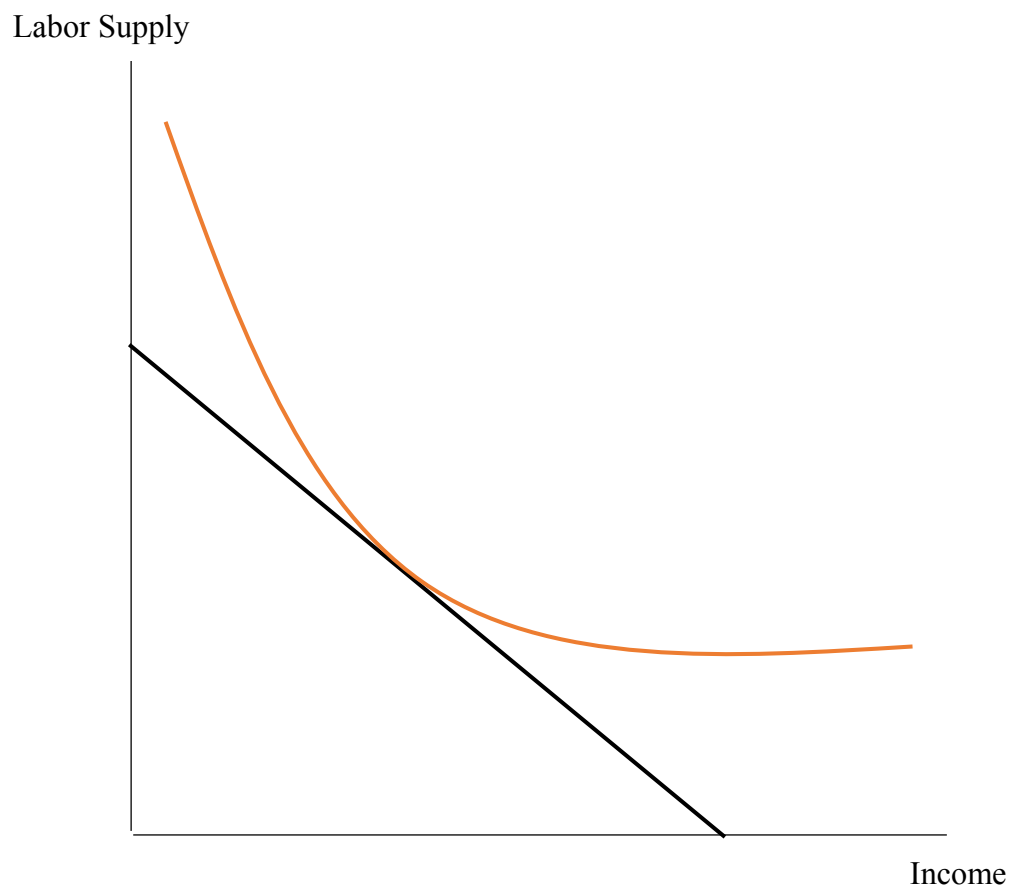

Figure 2. Income-labor supply curve.

labor supply and leisure goods under the constantly changing labor price, that is, the individual laborer's incentive response to changes in wage levels.

At the same time, the labor supply of taxi drivers also involves the empirical test of life cycle labor supply theory. Life cycle labor supply theory is the basic theory of modern economics. This theory points out the possibility of individual laborers making dynamic choices between consumption and leisure, which is conducive to a deeper understanding of how people solve problems caused by the government in the actual economic cycle. The short-term or long-term income fluctuations of individual laborers in the labor market caused by monetary policy, fiscal policy, and technological progress. According to this theory, laborers seek to maximize utility throughout their lives. Each individual laborer will pay more labor when wages rise, that is, increase labor supply, and when wages fall, reduce labor supply, that is, choose more leisure.

Economists have been trying to find evidence of backward bending in neoclassical economics in the real economic market. Although neoclassical economics and life cycle labor supply theory are intuitively correct, they are difficult to prove in reality. The main obstacle is that in the real society, since most individual workers are employed by companies to work, the working hours and wages of each worker are subject to the intervention and control of the company, industry, and local government, especially for most laborers. The commuting hours of the employees are all stipulated by the employers, and they cannot be determined and controlled by themselves, nor can they be determined by themselves through trade-offs to achieve a balance between labor supply and leisure. Many domestic research scholars have discussed the labor supply elasticity of 
individual laborers of different genders, different industries, and different age groups under real conditions. Most of these studies reflect the corresponding changes between laborers in different industries and different nature of work. The choice is not the decision made by individual non-workers to weigh the labor supply and leisure during the intertemporal labor cycle. Therefore, it is a realistic evidence to prove the labor supply theory of the life cycle, which still needs further research.

\subsubsection{The Current Situation of Labor Supply in the Taxi Industry}

This research is based on the current researches to find the evidence from the reality of life cycle labor supply theory by choosing the taxi driver as the labor individual in the taxi industry to choose between leisure and labor supply. The main reason is that in the taxi industry, drivers as suppliers in the labor market, can freely choose their own working hours, and their wages as the price of labor has always been fluctuating. Therefore, taxi drivers are an ideal object of labor supply decision-making research.

In the Chinese taxi industry, taxi drivers, as labor providers, during labor attacks, the trade-off between working hours and wages is also the result of their own optimal choices, rather than related restrictions within the industry. Taxi drivers use their daily expected income to decide whether to participate in work and how long they will work. However, when deciding whether to work, the driver cannot accurately predict the real wage level of the day, but can only make approximate judgments. At present, in most cities in China, many taxi drivers basically have no holidays and are often overloaded. There are two main explanations for this kind of phenomenon. One is that in China's labor market, the basic rights of labor suppliers, such as the right to rest, cannot be better protected. Taxi companies use different restrictive measures to exploit laborers. The surplus value prompts them to extend their working hours, obtain higher income and pay corresponding management fees. The other is that taxi drivers optimize their own labor time supply across time. In order to maximize their work benefits, many taxi drivers will choose to invest longer working hours in the day's work. Starting from the current status of China's taxi industry, the latter explanation is more realistic. The length of working hours of taxi drivers is more of their own choice, a decision made after weighing labor supply and leisure time. Wages refer to the remuneration that workers can obtain by providing a certain amount of labor within a certain period of time, that is, the price of labor. Wages can be classified into broad sense wages and narrow sense wages. Broad sense wages refer to the remuneration received by workers for all labor, including tangible and intangible labor, and all non-monetary benefits except monetary wages. Narrow wages are Refers to the remuneration received by workers. The labor supply behavior of taxi drivers belongs to the category of uncertain labor supply behavior. When providing labor, they will choose to provide different levels of labor due to the expected income, and rationally arrange labor 
supply and leisure for the purpose of maximizing utility. .

At present, many cities in China, such as Shanghai, are experiencing a decline in the relative income of taxi drivers. The rental market has the characteristics of monopolistic competition. Although the taxi market is a monopolistic market, monopoly does not eliminate free competition, but makes competition more intense. From the perspective of taxi drivers, if the benefits cannot be fully guaranteed, on the one hand, the number of young people as taxi drivers will decrease, that is, young people will reduce the labor supply, which will cause problems in the replacement of the industry. On the one hand, existing drivers choose to quit, and the number of existing drivers decreases. From the perspective of the rental company, although the number of drivers has decreased and the revenue has decreased, the market is a monopolistic market that cannot enter and exit at will, and still needs to continue operating. To a certain extent, taxi companies are weak in the game. However, in fact, the relative income of taxi drivers is on a downward trend in many cities. The main reason is that taxi drivers have less bargaining chips in negotiations with taxis. In particular, the current situation in the taxi industry in our country where taxi companies have an important resource of taxi operation permits has further hindered taxi drivers from making reasonable choices in labor supply and leisure.

\section{Models and Predictions}

\subsection{Neoclassical Model of Labor Supply}

In the neoclassical model, an agent receives utility by enjoying both income (I) and leisure time $(L)$. Moreover, it is assumed that agent's utility $U(I, L)$ is concave in both $I$ and $L$. To make the analysis tractable, it is common to assume that the utility is separable in $I$ and $L$, that is $U(I, L)=U_{1}(I)+U_{2}(L)$. Since most analyses focus on the work hours $(H)$, alternatively, we can represent leisure $L$ as $24-H$, or directly write $U_{2}(H)$ instead.

Given a fix rate of return, hourly wage, $w$, agents' income can be calculated as $I=w H$. An agent needs to optimize the total utility over work hours $H$ by solving the first order condition (FOC) of the utility maximization problem, i.e.,

$$
\begin{gathered}
\max U_{1}(I)+U_{2}(H) \\
\text { s.t. } I=w H
\end{gathered}
$$

The FOC with respect to work hours $H$ becomes $w U_{1}^{\prime}(I)+U_{2}^{\prime}(H)=0$. The first term is an agent's marginal utility of income and the second term is the marginal utility of leisure (note $H=24-L$ ). It can be written as $w=-U_{2}^{\prime}(H) / U_{1}^{\prime}(I)$. That is how an agent evaluates his/her ratio of the marginal utility of leisure to the marginal utility of income and equalize it to the hourly wage at the optimal decision on work hours. When wage increases, the ratio should also increase. Hence, the neoclassical model predicts that the wage elasticity of labor supply is positive, i.e., there should be more taxis when hourly wage is higher, and vice versa. In addition, the ratio of $-U_{2}^{\prime}(H) / U_{1}^{\prime}(I)$ denotes the slope of the indif- 
ference curve of the tradeoff between income and working hours facing by the driver. It is illustrated in Figure 3.

However, Camerer, Babcock, Loewenstein and Thaler (1997) shows that this elasticity of labor supply is negative using NYC taxi drivers data, which contradict to what the neoclassical theory predicts.

\subsection{Reference-Dependent Model with Income Target}

To reconcile the observation in the NYC taxi drivers and the theoretical prediction Camerer, Babcock, Loewenstein and Thaler (1997) propose a behavioral model with loss-averse utility. The loss-averse utility of drivers assumes they set an income target, and continue to work until the target is reached. In particular, the utility function of this form can be written as

$$
(1-\eta)\left(U_{1}(I)+U_{2}(L)\right)+\eta R\left(I \mid I^{r}\right)
$$

where $R\left(I \mid I^{r}\right)$ is the gain-loss utility and $\eta$ is the weight. And

$$
R\left(I \mid I^{r}\right)=1_{\left(I-I^{r}<0\right)} \lambda\left(U_{1}(I)-U_{1}\left(I^{r}\right)\right)+1_{\left(I-I^{r}>0\right)}\left(U_{1}(I)-U_{1}\left(I^{r}\right)\right)
$$

For the gain-loss utility term $R\left(I \mid I^{r}\right)$, if an agent has not met his/her income target, the agent gets disutility equal to $\lambda\left(U_{1}(I)-U_{1}\left(I^{r}\right)\right)$. Otherwise, the agent's utility is $\left(U_{1}(I)-U_{1}\left(I^{r}\right)\right)$. Since agents dislike loss relative to the target income level, it is generally assumed that $\lambda>1$.

Given this utility, an agent needs to optimize over work hours $H(=24-L)$ to maximize his/her utility function, that is

$$
\begin{gathered}
\max (1-\eta)\left(U_{1}(I)+U_{2}(L)\right)+\eta R\left(I \mid I^{r}\right) \\
\text { s.t. } H=w I
\end{gathered}
$$

The first order condition w.r.t. $H$ then depends on whether the target is met or not. If income target is not met, i.e., $I<I^{r}$, FOC is

$$
(1-\eta)\left(w U_{1}^{\prime}(I)+U_{2}^{\prime}(H)\right)+\eta \lambda w U_{1}^{\prime}(I)=0
$$

This can be further simplified as $w=-\left[(1-\eta) U_{2}^{\prime}(H)\right] /\left[(1-\eta+\eta \lambda) U_{1}^{\prime}(I)\right]$. Otherwise, when $I>I^{r}$, FOC is $(1-\eta)\left(w U_{1}^{\prime}(I)+U_{2}^{\prime}(H)\right)+\eta w U_{1}^{\prime}(I)=0$, which can be written as $w=-\left[(1-\eta) U_{2}^{\prime}(H)\right] / U_{1}^{\prime}(I)$. Since $\lambda>1$ implies $1-\eta+\eta \lambda>1$, agent's marginal utility is lower when income target is not met. As the agent achieves the optimal work hours by choosing the ratio of marginal utility of leisure relative to income equal to wage, given the same hourly rate, the agent need to work more time when the income target is not met. Apparently, there is a kink in the ratio when the income is below and above the target. To illustrate it, we assume the ratio is constant when the income is below and above the target income level and illustrate the change in Figure 4.

The loss aversion refers to agent higher marginal disutility when income is below the target level comparing with the marginal disutility when income is above the target level. Nonetheless, there is not much empirical evidence supporting the income-level reference based models. 


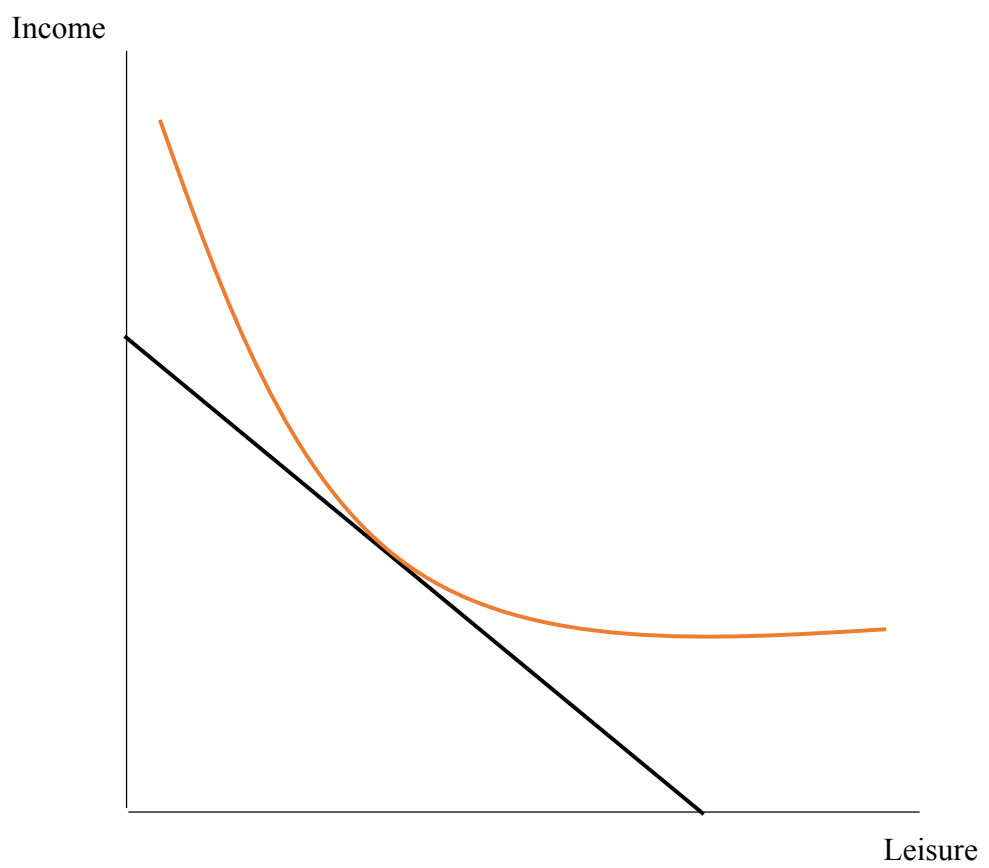

Figure 3. Neoclassical model.

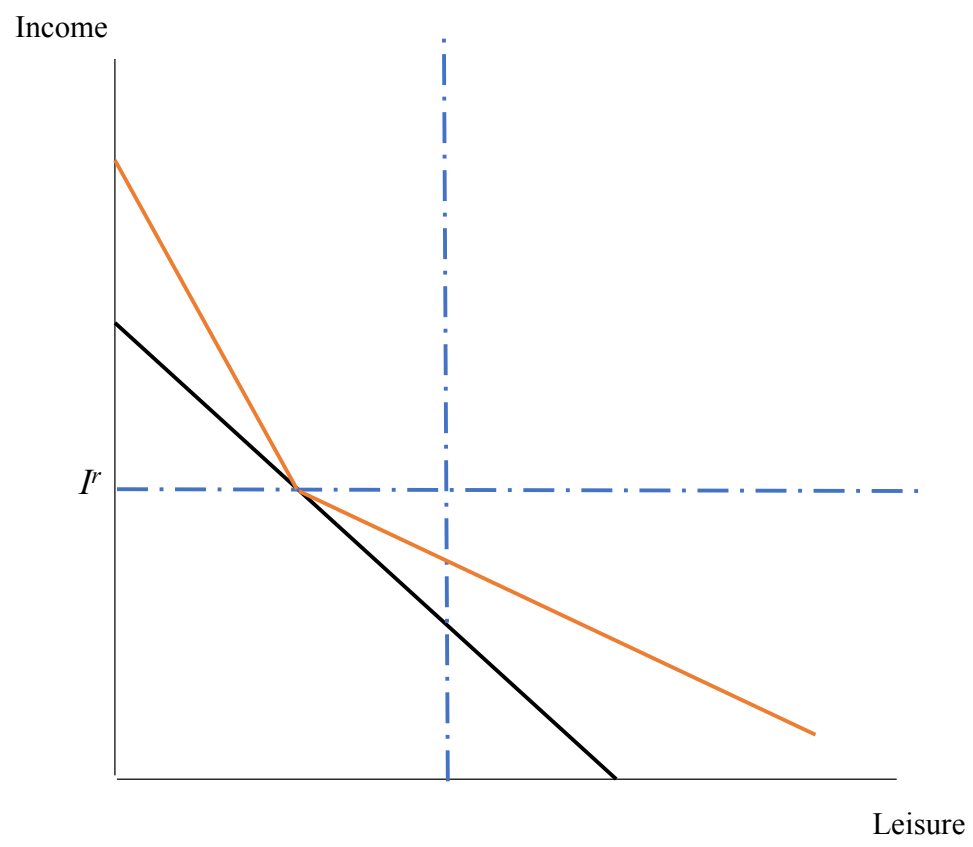

Figure 4. Income reference model.

\subsection{Reference-Dependent Model with Work Hours Target}

Farber (2005) examines the NYC taxi driver's data consisting of work hours and income. He finds that there is little evidence supporting the income-level reference based models. Instead, taxi drivers are likely to stop working when reaching certain total hours. Farber (2005) neither supports nor rejects a reference based model with total work hours as target. For completeness, we will also test this 
model.

In analogy to model 2 , the utility maximization problem becomes

$$
\begin{gathered}
\max (1-\eta)\left(U_{1}(I)+U_{2}(L)\right)+\eta R\left(H \mid H^{r}\right) \\
\text { s.t. } H=w I
\end{gathered}
$$

where

$$
R\left(H \mid H^{r}\right)=1_{\left(H-H^{r}<0\right)} \lambda\left(U_{2}(H)-U_{2}\left(H^{r}\right)\right)+1_{\left(H-H^{r}>0\right)}\left(U_{2}(H)-U_{2}\left(H^{r}\right)\right) .
$$

Similarly, FOC is $(1-\eta)\left(w U_{1}^{\prime}(I)+U_{2}^{\prime}(H)\right)+\eta \lambda U_{2}^{\prime}(H)=0$ or $w=-\left[(1-\eta+\eta \lambda) U_{2}^{\prime}(H)\right] /\left[(1-\eta) U_{1}^{\prime}(I)\right]$ when $H>H^{r}$ and $(1-\eta)\left(w U_{1}^{\prime}(I)+U_{2}^{\prime}(H)\right)+\eta U_{2}^{\prime}(H)=0$ or $w=-U_{2}^{\prime}(H) /\left[(1-\eta) U_{1}^{\prime}(I)\right]$.

The analysis of this model is similar as that in model 2, with a kink in the difference curve. It is illustrated in Figure 5.

\subsection{Reference-Dependent Model with Both Income and Work Hours as Targets}

Some papers, i.e., Camerer et al. (1997), Crawford and Meng (2011), then suggest that these finds can be explained better with reference-dependent model. The reference-dependent model allows individuals to have either income or hours or both as targets.

Farber (2005) examines the NYC taxi driver's data consisting of work hours and income. He finds that there is little evidence supporting the income-level reference-based models. Instead, taxi drivers are likely to stop working when reaching certain total hours worked. Farber (2005) neither supports nor rejects a reference-based model with total work hours as target.

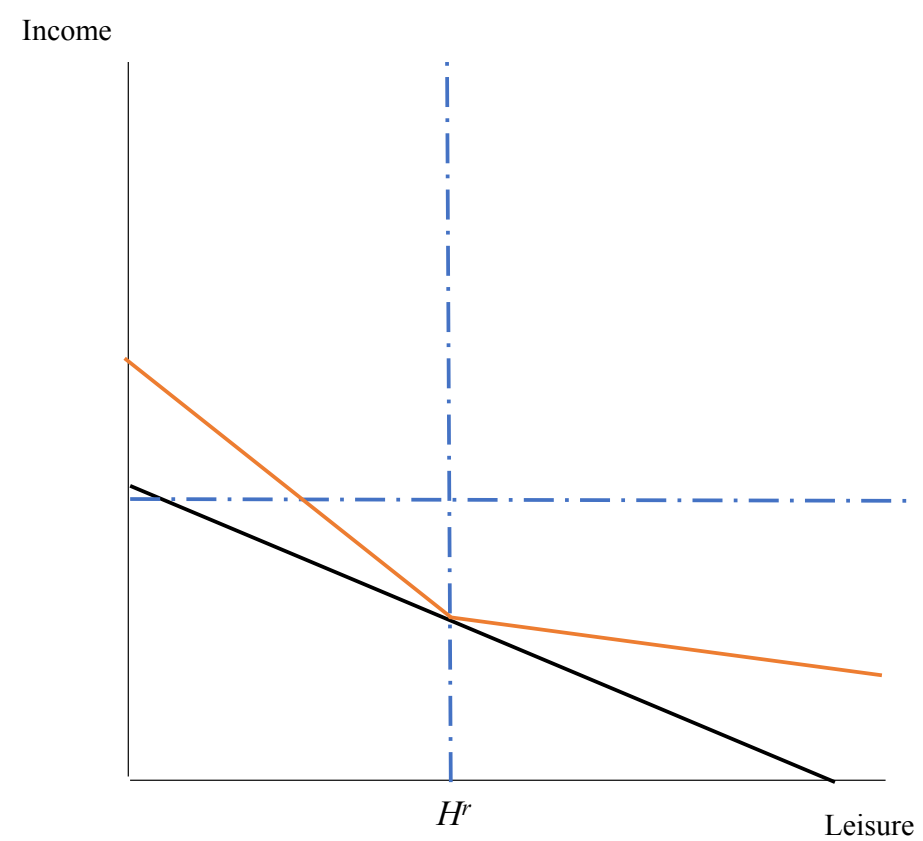

Figure 5. Work hours reference model. 
The literature on labor supply then moves on to the model with more flexibility of reference points with both income and hour as targets, e.g., Farber (2008) and Crawford and Meng (2011). The utility function to be maximized is

$$
(1-\eta)\left(U_{1}(I)+U_{2}(L)\right)+\eta R\left(I, H \mid I^{r}, H^{r}\right)
$$

with gain-loss function

$$
\begin{aligned}
R\left(I, H \mid I^{r}, H^{r}\right)= & 1_{\left(I-I^{r}<0\right)} \lambda\left(U_{1}(I)-U_{1}\left(I^{r}\right)\right)+1_{\left(I-I^{r}>0\right)}\left(U_{1}(I)-U_{1}\left(I^{r}\right)\right) \\
& +1_{\left(H-H^{r}<0\right)} \lambda\left(U_{2}(H)-U_{2}\left(H^{r}\right)\right)+1_{\left(H-H^{r}>0\right)}\left(U_{2}(H)-U_{2}\left(H^{r}\right)\right)
\end{aligned}
$$

The FOC, hence, depends on both targets being met or not:

1) $I<I^{r}$ and $H<H^{r}: w=-U_{2}^{\prime}(H) /\left[(1-\eta+\eta \lambda) U_{1}^{\prime}(I)\right]$

2) $I>I^{r}$ and $H<H^{r}: w=-U_{2}^{\prime}(H) / U_{1}^{\prime}(I)$

3) $I<I^{r}$ and $H>H^{r}: w=-U_{2}^{\prime}(H) / U_{1}^{\prime}(I)$

4) $I>I^{r}$ and $H>H^{r}$ : $w=-\left[(1-\eta+\eta \lambda) U_{2}^{\prime}(H)\right] / U_{1}^{\prime}(I)$

In this case, the ratio of marginal utility of leisure and income has two kinks at two targets, respectively. In addition, the optimal decision of work hours of a driver could involve either of these two targets depending on the hourly rate wage $w$.

As illustrated in Figure 6, two indifference curves with the lower one representing a "bad" day (low hourly rate) and the higher one representing a "good" day. Theoretically, drivers can stop working by hitting any targets, Figure 6 is constructed to illustrate the finding in the dataset of Crawford and Meng (2011), in which, drivers are likely to stop working by reaching the second target,

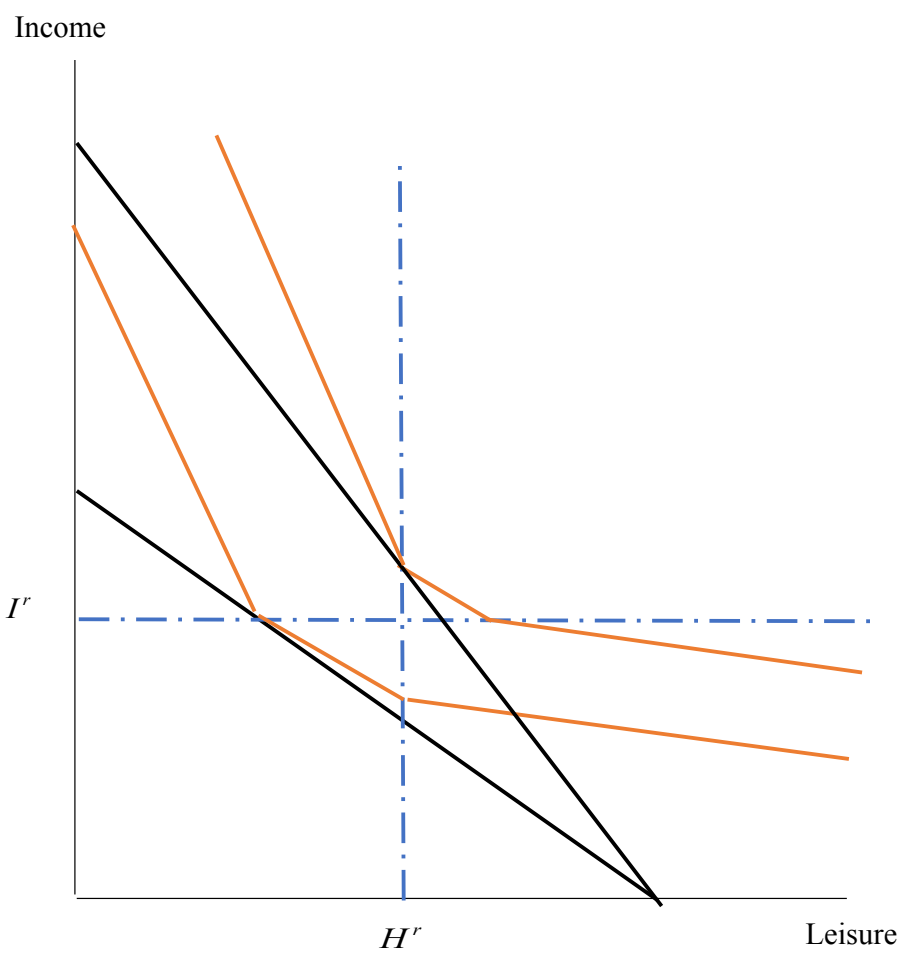

Figure 6. Income and work hour reference model. 
which is driver's income target. In particular, drivers stop working by reaching the income target during "bad" day. On the other hand, the second reference point is hour-target during a "good" day.

This theory predicts that labor supply is nonmonotonic. When expected earnings per hour is very low, the higher cost of income loses increases the incentive to work above the neoclassical level. When the income target is reached second, the elasticity of hours with respect to expected earnings per hour is negative. When expected earnings per hour is very high, the higher cost of hours losses decreases the incentive to work below its neoclassical level.

\section{Conclusion}

This article has conducted a qualitative analysis of the labor force and wages of taxi drivers. The neoclassical labor supply theory comprehensively believes that working hours should respond positively to short-lived positive wage changes. However, according to the reference dependence preference theory, people's choices depend on the judgment of the reference point. In decision-making, the theory of reference dependence preference holds that people's decision-making is not based on absolute quantity, but largely influenced by the comparison with reference points. In this circumstance, people's decision-making behavior will be affected by reference dependence, loss aversion, and diminishing marginal sensitivity. Psychology believes that people often hide a latent evaluation standard when making decisions, and this standard is the reference point. The reference point is a comparison object which can be peers, similar products, or things encountered before. The formation of a reference point can also be an expectation of price, which is formed by summing up historical experience and combining the current environment.

This article summarizes the various research results on the behavior of labor supply in the existing literature from both theoretical and practical aspects. Through the literature review and combined with the study on current development status of China's taxi industry, this paper made a study on the elasticity of labor supply of Chinese taxi drivers. According to the perspective of the reference dependence theory, in the taxi industry, taxi drivers have certain expectations of daily income, and the utility loss of not reaching the goal will be greater than the utility when exceeding the expected value, so that taxi drivers are loss-averse. When the average expectation is reached, the desire of taxi drivers to work will decrease, and they may even end their work earlier. This phenomenon is different from the first image which is an extreme case of reference-dependent preference behavior. It is important for the Chinese local government to understand the economic principles behind the taxi drivers' behavior that they can develop local transport system including the taxi industry more properly.

\section{Conflicts of Interest}

The author declares no conflicts of interest regarding the publication of this paper. 


\section{References}

Abowd, J. M., \& Card, D. (1984). Intertemporal Substitution in the Presence of Long Term Contracts. Working Papers.

Kőszegi, B., \& Rabin, M. (2006). Dynamic Reference-Dependent Preferences 1. MIT Press.

Cai, F., \& Wang, M. (2001). The Characteristics of Female Labor Supply and Education Investment. Jiang Hai Journal, No. 6, 35-39.

Camerer, C., Ba Bcock, L., Loewenstein, G., \& Thaler, R. (1997). Labor Supply of New York City Cabdrivers: One Day at a Time. The Quarterly Journal of Economics, 112, 407-441. https://doi.org/10.1162/003355397555244

Crawford, V. P., \& Meng, J. (2011). New York City Cab Drivers' Labor Supply Revisited: Reference-Dependent Preferences with Rational-Expectations Targets for Hours and Income. American Economic Review, 101, 1912-1932.

https://doi.org/10.1257/aer.101.5.1912

Doran, K. (2014). Are Long-Term Wage Elasticities of Labor Supply More Negative than Short-Term Ones? Economics Letters, 122, 208-210.

https://doi.org/10.1016/j.econlet.2013.11.023

Du, Y., \& Qu, Y. (2009). Labor Remuneration, Labor Productivity and Labor Cost Advantages-An Empirical Study of Chinese Manufacturing Enterprises from 2000 to 2007. China Industrial Economics, No. 5, 25-35.

Farber, H. (2005). Is Tomorrow Another Day? The Labor Supply of New York City Cabdrivers. Journal of Political Economy, 113. https://doi.org/10.1086/426040

Farber, H. (2008). Reference-Dependent Preferences and Labor Supply: The Case of New York City Taxi Drivers. American Economic Review, 98, 1069-1082. https://doi.org/10.1257/aer.98.3.1069

Farber, H. (2015). Why You Can't Find a Taxi in the Rain and Other Labor Supply Lessons from Cab Drivers. Quarterly Journal of Economics, 130, 1975-2026.

https://doi.org/10.1093/qje/qjv026

Fehr, E., \& Goette, L. (2007). Do Workers Work More if Wages Are High? Evidence from a Randomized Field Experiment. American Economic Review, 97, 298-317. https://doi.org/10.1257/aer.97.1.298

Guo, K. (2000). Structural Optimization and Efficient Development of the Tertiary Industry (Part I). Finance \& Trade Economics, No. 11, 30-34.

Li, L. (2005). A Review of Researches on the Impact of Pension Funds on Labor Supply. Science of Finance and Economics, No. 4, 175-180.

Lin, S., Lan, W., Wu, H., Lu, Y., \& The Joint Task Team of Fujian Investigation Team and Zhangzhou Investigation Team (2013). Research on the Relationship between Residents' Wage Income and Labor Productivity: Taking Fujian as an Example. Survey World, 6, 5-11.

Lu, F. (2007). Economic Observation of Contemporary Service Outsourcing: An Analytical Perspective of Intra-product Division of Labor. The Journal of Economy, No. 8, 22-35.

Lucas, R., \& Rapping, L. (1969). Real Wages, Employment, and Inflation. Journal of Political Economy, 77, 721-754. https://doi.org/10.1086/259559

Luo, Z., \& Zhao, Q. (2013). Why Does China's High Investment and Low Labor Income Coexist?-The Perspective of Labor Productivity and Wage Growth Gap. World Economic Papers, No. 6, 1-13. 
Oettinger, G. (1999). An Empirical Analysis of the Daily Labor Supply of Stadium Venors. Journal of Political Economy, 107, 360-392. https://doi.org/10.1086/250063

$\mathrm{Xu}, \mathrm{K}$. (2016). Research on the Relationship between Labor Pay Increase and Labor Productivity Increase. Nanjing University of Finance and Economics.

Zhang. J., \& Liu, X. (2012). The Relationship between Wages and Labor Productivity: Models and Explanations. Social Science Journal of Harbin Institute of Technology, No. 2, 89-100.

Zheng, Y. (2012). Research on the Relationship between Labor Compensation and Production Efficiency in Guangdong Province. Doctoral Dissertation, Guangdong University of Business Studies. 